\title{
Observations of Stratosphere-Troposphere Coupling During Major Solar Eclipses from FORMOSAT-3/COSMIC Constellation
}

\author{
Kuo-Ying Wang • Chao-Han Liu • Lou-Chuang Lee • \\ Peter Braesicke
}

Received: 30 May 2011 / Accepted: 27 August 2011 / Published online: 28 October 2011

(C) The Author(s) 2011. This article is published with open access at Springerlink.com

\begin{abstract}
Sudden tropospheric cooling and induced stratospheric warming were found during the 22 July 2009 total solar eclipse. Can the 22 July 2009 hallmark also be seen in other major solar eclipses? Here we hypothesize that the tropospheric cooling and the stratospheric warming can be predicted to occur during a major solar eclipse event. In this work we use the FORMOSAT-3/COSMIC (F3C) Global Positioning System (GPS) radio occultation (RO) data to construct eclipse-time temperature profiles before, during, and after the passages of major solar eclipses for the years 2006-2010. We use four times a day of meteorological analysis from the European Centre for Medium Range Weather Forecast (ECMWF) global meteorological analysis to construct non-eclipse effect temperature profiles for the same eclipse passages. The eclipse effects were calculated based on the difference between F3C and ECMWF profiles. A total of five eclipse cases and thirteen non-eclipse cases were analyzed and compared. We found that eclipses cause direct thermal cooling in the troposphere and indirect dynamic warming in the stratosphere. These results are statistically significant. Our results show -0.6 to $-1.2^{\circ} \mathrm{C}$ cooling in the troposphere and 0.4 to $1.3^{\circ} \mathrm{C}$ warming in the middle to lower stratosphere during the eclipses. This characteristic stratosphere-troposphere coupling in temperature profiles represent a distinctive atmospheric responses to the solar eclipses.
\end{abstract}

Keywords Solar eclipse $\cdot$ Stratosphere-troposphere coupling $\cdot$ FORMOSAT-3/COSMIC · ECMWF

\footnotetext{
K.-Y. Wang ( $\square)$

Department of Atmospheric Sciences, National Central University, Chung-Li, Taiwan

e-mail: kuoying@mail.atm.ncu.edu.tw

C.-H. Liu - L.-C. Lee

Institute of Space Science, National Central University, Chung-Li, Taiwan

P. Braesicke

Centre for Atmospheric Science, Department of Chemistry, Cambridge University, Lensfield Road,

Cambridge, CB2 1EW, UK
} 


\section{Introduction}

Major solar eclipses such as total solar eclipse and annular solar eclipse arise from direct block out of incoming solar radiation by the moon to the atmosphere (Zirker 1980; Lindsey et al. 1992; Pasachoff 2009). This sudden drop in the incoming solar radiation causes the cooling of the surface and higher up, resulting in the changes of atmospheric temperatures. These temperature variations drive changes in pressures and winds (Ballard et al. 1969; Anderson et al. 1972; Founda et al. 2007; Gerasopoulos et al. 2007; Kameda et al. 2009; Wang and Liu 2010), and induces vertically propagating gravity waves (e.g., Chimonas 1970; Chimonas and Hines 1971; Seykora et al. 1985; Zerefos et al. 2007). Solar eclipse also changes the ionosphere total electron density (Le et al. 2009). Treumann et al. (2008) described the physics of electric discharges in the atmospheric gases, and average altitude profiles of temperature and mass density from the surface to $150-\mathrm{km}$ altitude.

Though the troposphere and the stratosphere are regarded as a coupled system (Holton et al. 1995), the effects of the eclipse on this coupled system is not well known, due to the lack of observational data from the troposphere to the stratosphere when the lunar shadows move through the atmosphere.

Wang and Liu (2010) used F3C data to study the atmospheric effect of the 22 July 2010 total solar eclipse. They found a significant cooling through the troposphere and a distinctive warming in the lower stratosphere. This sudden tropospheric cooling and stratospheric warming appeared as a hallmark in the coupled stratosphere-troposphere system during the 22 July 2009 total solar eclipse. Can the 22 July 2009 hallmark also be seen in other major solar eclipses? Here we hypothesize that the tropospheric cooling and the stratospheric warming can be predicted to occur during a major solar eclipse event. The motivation for this study is to use F3C GPS RO data, together with the daily ECMWF global meteorological analysis, to demonstrate that the tropospheric cooling and stratospheric warming feature is indeed a hallmark during a major solar eclipse.

\section{Data and Methods}

\subsection{The 2006-2010 Solar Eclipses}

Table 1 shows a list of five major solar eclipse events that had occurred between September 2006 and January 2010. Figure 1 shows spatial distribution of the 15 January 2010, 26 January 2009, 1 August 2008, and 22 September 2006 solar eclipse paths, and distribution of the GPS RO profiles. Here the green dots indicate all the GPS RO profiles that are located within the 3-hour time window of the 1-s eclipse centers, the red dots indicate all the GPS $\mathrm{RO}$ profiles that are within $2250-\mathrm{km}$ radius of the eclipse path, and the blue dots indicate

Table 1 Major solar eclipses analyzed in this work (Espenak and Meeus 2006; Espenak and Anderson 2008)

\begin{tabular}{lll}
\hline Time & Event & Region \\
\hline 22 September 2006 & Annular solar eclipse & South Atlantic Ocean \\
1 August 2008 & Total solar eclipse & Northern Polar regions-Central Asia \\
26 January 2009 & Annular solar eclipse & South Indian Ocean \\
22 July 2009 & Total solar eclipse & South Asia-North Pacific Ocean \\
15 January 2010 & Annular solar eclipse & East Africa-North Indian Ocean \\
\hline
\end{tabular}


(a)

FORMOSAT-3 PROFILES ON 15 JAN 2010 GREEN RED BLUE $669 \quad 105 \quad 20$

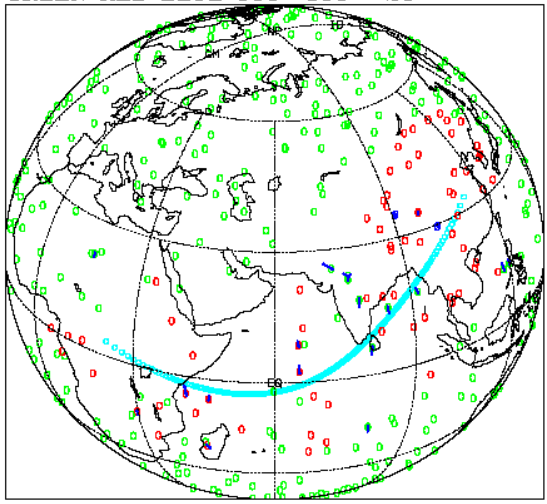

FORMOSAT -3 PROFILES ON 26 JAN 2009 GREEN RED BLUE $1116 \quad 266 \quad 55$

(b)

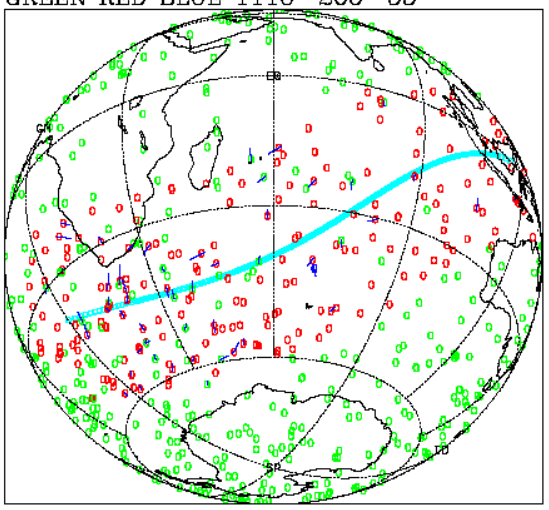

FORMOSAT-3 PROFILES ON 1 AUG 2008 GREEN RED BLUE $604 \quad 176 \quad 43$

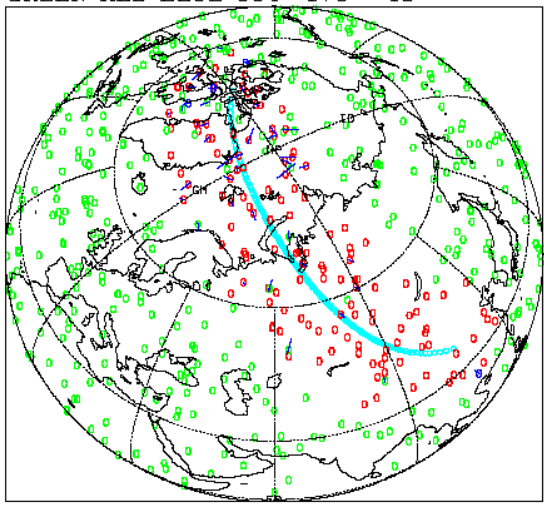

FORMOSAT-3 PROFILES ON 22 SEP 2006 GREEN RED BLUE $665 \quad 121 \quad 33$

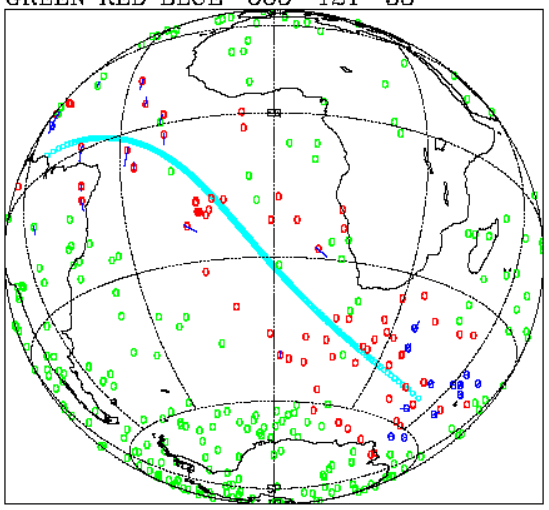

Fig. 1 Spatial distribution of F3C GPS RO profiles and path of the total eclipse (sky-blue circles) on (a) 15 January 2010, (b) 26 January 2009, (c) 1 August 2008, and (d) 22 September 2006. RO profiles located within 3-hour time window of the 1-s eclipse centers are shown in green dots, within a distance of $2250-\mathrm{km}$ radius are shown in red circles, within both 3-hour time window and 2250-km radius are shown in blue circles and its ray path in blue lines

all the GPS RO profiles that are within the 3-hour time window and 2250-km radius of the eclipse centers calculated by Espenak and Meeus (2006). Only the blue dots were selected for analysis. The locations of these blue dots were also used to select ECMWF grids that coincide with the GPS RO locations. The path of the 22 July 2009 eclipse and the distribution of the GPS RO profiles were shown in Wang and Liu (2010).

In this work we select only major eclipse events and the periods of the events that were covered by the availability of the $\mathrm{F} 3 \mathrm{C}$ data. Two total solar eclipses occurred in this period. One occurred on 1 August 2008, during the Northern Hemisphere (NH) summer, covering polar regions of Greenland, North Atlantic, and mid-latitude of Central Asia (Fig. 1(c)). The second one occurred on 22 July 2009 also during the NH summer, covering latitudinal bands between equator and $30^{\circ} \mathrm{N}$ of the Asian and Pacific regions (see Fig. 1 of Wang and Liu 2010). The rest three are annular solar eclipses. The 22 September 2006 annular solar eclipse occurred over the Southern Hemisphere (SH), covering latitudes from equator to $60^{\circ} \mathrm{S}$, and regions of South Atlantic Ocean (Fig. 1(d)). The 26 January 2009 annular solar eclipse occurred over the $\mathrm{SH}$ as well, covering latitudes between $45^{\circ} \mathrm{S}$ to equator and regions of 
South Indian Ocean (Fig. 1(b)). The 15 January 2010 annular solar eclipse covered regions from East Africa, through North Indian Ocean to Southeast Asia and China (Fig. 1(a)).

The eclipse paths shown in Fig. 1 represent centers of lunar shadows as the lunar shadow moves through the atmosphere. These are the locations where the maximum effect of moon's block out of solar radiation occurred. For example, during a total solar eclipse, the center of the eclipse represents $100 \%$ block out of the sun. The percentage of block out decreases as distance to the center of the eclipse increases.

\subsection{Eclipse-Effect Recording GPS RO Profiles: The Eclipse-Time Mean Temperature Differences $d T(\mathrm{~F} 3 \mathrm{C})$}

The successful launch of the F3C satellite on 14 April 2006 provides a new way to measure temperature profiles in the troposphere and the stratosphere on a global domain (Anthes et al. 2008). The GPS RO method provides highly accurate temperature profiles from the middle troposphere to the stratosphere (Kursinski et al. 1997; Wickert et al. 2001; Hajj et al. 2004; Kuo et al. 2005). The high spatial and temporal coverage of the GPS RO profiles enable us to study the atmospheric effects of prominent events that were previously difficult to investigate. For example, effects of the volcanic plumes following volcano eruption (Wang et al. 2009), thermal effects of the Saharan dust over the tropical North Atlantic (Wang 2010), high resolution vertical temperature structure inside the Antarctic polar vortex (Wang and Lin 2007), large-scale planetary waves (Shepherd and Tsuda 2008), and variability of the upper troposphere and lower stratosphere (e.g., Schmidt et al. 2010).

The F3C data set used in this work are the same as those described in Wang and Liu (2010). This work used Level-2 post-processed atmospheric temperature profiles obtained from F3C data center at Taiwan Analysis Center for COSMIC (TACC; http://tacc.cwb.gov.tw). Each F3C RO profile contains a vertical 1-km resolution, extending from the surface to $40-\mathrm{km}$ altitude.

In order to estimate the effect of the major eclipses on the stratosphere-troposphere coupled system, we calculate and compare temperature profiles before, during, and after the eclipse. We note that the selections of the FORMOSAT-3/COSMIC data along the vicinity of the eclipse paths were followed the method described in Wang and Liu (2010). Basically, the F3C GPS RO profiles were selected when if it occurred within a 3-hour time window, and $2250-\mathrm{km}$ distance in space between the RO points and the centers of the eclipse. For simplicity of following discussion, we call these profiles as the eclipse-effect recording RO profiles.

Firstly, we take profiles of eclipse-time GPS RO temperature measurements inside the lunar shadow as it moves through the atmosphere. These represent temperature profiles inside the real lunar shadows. Secondly, we take temperature profiles following the same eclipse path but on non-eclipse days. These temperatures are calculated as follows. Let $T_{i, k, l}^{\mathrm{F} 3 \mathrm{C}} \mathrm{de}-$ notes temperature profiles from F3C. Here $i$ indicates GPS RO profile index, and $k$ indicates a vertical level index for each GPS RO profile. Here $l$ indicates day index for each eclipse event, including 10 days before a major eclipse, during the eclipse day, and 10 days after the eclipse day. Details of these days for each major eclipse event are shown in Table 2. Hence, the mean temperature profiles for each day in the investigated period (10 days before and 10 days after an eclipse) is given by

$$
\overline{T_{k, l}^{\mathrm{F} 3 \mathrm{C}}}=\frac{\sum_{i=1}^{M} T_{i, k, l}^{\mathrm{F} 3 \mathrm{C}}}{M}
$$


Table 2 Analysis periods

\begin{tabular}{lllll}
\hline Pre-eclipse days & Eclipse day & Post-eclipse days & Eclipse year & Comparison years \\
\hline 12 Sep-21 Sep & 09:52-13:27 UT, 22 Sep & 23 Sep-2 Oct & 2006 & 2007, 2008, 2009 \\
22 Jul-31 Jul & 09:23-11:18 UT 1 Aug & 2 Aug-11 Aug & 2008 & 2007,2009 \\
16 Jan-25 Jan & 06:07-09:50 UT, 26 Jan & 27 Jan-5 Feb & 2009 & $2007,2008,2010$ \\
12 Jul-21 Jul & 00:53-04:17 UT, 22 Jul & 23 Jul-1 Aug & 2009 & 2007,2008 \\
5 Jan-14 Jan & 05:18-08:54 UT, 15 Jan & 16 Jan-25 Jan & 2010 & $2009,2008,2007$ \\
\hline
\end{tabular}

Here $M$ is the total number of GPS RO profiles that had occurred in the 3-h time-window and the $2250-\mathrm{km}$ vicinity of the eclipse centers. These are the eclipse-effect recording RO profiles. In the comparing non-eclipse years, no eclipse had occurred but we still take temperature profiles inside a virtual lunar shadow as it moves through the atmosphere. Note that the virtual lunar shadows and the real lunar shadows are exactly the same, except that the block out of solar radiation occurred only inside the real lunar shadows.

Equation (1) was applied to both the eclipse year and the comparing non-eclipse years for each of the five major solar eclipses shown in Table 2. Based on (1), we can calculate the mean eclipse-time temperature difference profiles between the eclipse day and the noneclipse days as:

$$
\overline{d T_{k}^{\mathrm{F} 3 \mathrm{C}}}=\frac{\sum_{l=1}^{L} \overline{T_{k, \mathrm{eclipse} \mathrm{day}}^{\mathrm{F} C}}-\overline{T_{k, l}^{\mathrm{F} 3 \mathrm{C}}}}{L}
$$

Here $L$ is equal to 20 ( 10 days before and after the eclipse day). These profiles of temperature differences are also denoted as $d T(\mathrm{~F} 3 \mathrm{C})$. Hence,

$$
d T(\mathrm{~F} 3 \mathrm{C})=\overline{d T_{k}^{\mathrm{F} 3 \mathrm{C}}}
$$

The GPS RO data from F3C provides temperature profiles inside the lunar shadows at eclipse days $\left(\overline{T_{k \text {,eclipse day }}^{\mathrm{F} C}}\right)$, and inside the virtual lunar shadows at the non-eclipse days $\left(\overline{T_{k, l}^{\mathrm{F} C}}\right)$. Since all the GPS RO data were taken during the day time when eclipse occurred, these profiles represent eclipse-time mean temperatures $(d T(\mathrm{~F} 3 \mathrm{C}))$.

Table 2 shows a list of days for calculating the F3C-based eclipse-time mean temperatures inside the lunar shadow (eclipse day), and inside the virtual lunar shadows at the non-eclipse days (pre-eclipse days and post-eclipse days) for the eclipse year. For the comparison purpose, we also calculate the temperature difference along the same eclipse path for the same period but in non-eclipse years (comparison years). Note that an eclipse occurred only in the eclipse year and not in the non-eclipse years. The eclipse-time mean temperatures were calculated following the eclipse path and vicinity (Fig. 1) for each day of both the eclipse year and the comparison years shown in Table 2.

\subsection{Non-eclipse Effect Analysis Profiles: The Daily Mean Temperature Differences $d T(\mathrm{ECMWF})$}

We note that temperature profiles are also influenced by the atmospheric dynamic processes associated with the synoptic scale weather activity (e.g., advection of warm and cold airs), and the atmospheric physical processes such as the diabatic cooling/warming associated with the presence of the aerosols (e.g., Wang et al. 2009). 
Fig. 2 (a) Spatial distribution of ECMWF grid profiles (red dots) and path of the total eclipse (sky-blue circles) on 15 January 2010. (b) The same as in (a) but also for F3C GPS RO profiles (big blue circles)

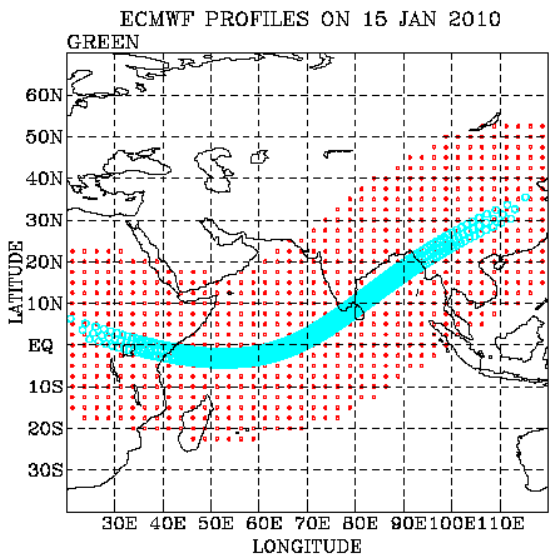

(a)

$$
\text { FS3 and EC PROFILES ON } 15 \text { JAN } 2010
$$

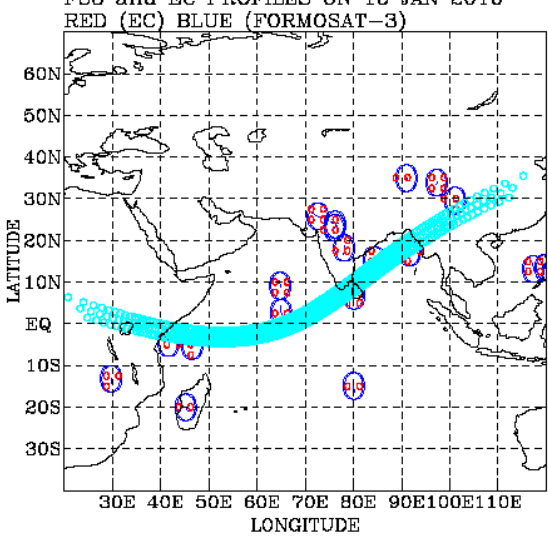

In order to quantify these non-eclipse effects, we use four times (at 00, 06, 12, and 18 UT) a day of meteorological analysis taken from the ECMWF (Buizza et al. 2005) to help define the variations of the daily average (basic state) of the atmosphere. The current operational ECMWF forecast model contains a horizontal resolution of $0.125^{\circ} \times 0.125^{\circ}$ longitude/latitude, and a vertical resolution of 91 layers, extending from the surface up to $0.01 \mathrm{hPa}$ (about $80 \mathrm{~km}$ ). In this work we use four times daily global gridded data product, which contains horizontally a $2.5^{\circ} \times 2.5^{\circ}$ longitude-latitude grid resolution, and at levels 1000, 950, 925, 900, 850, 800, 700, 600, 500, 400, 300, 250, 200, 150, 100, 70, 50, 30, $20,10,7,5,3,2$, and $1 \mathrm{hPa}$. More detailed information on the evolution of the ECMWF forecast system can be found at ECMWF (see http://www.ecmwf.int). These 6-hourly analysis data are vertically interpolated to the $1-\mathrm{km}$ vertical resolution used in the $\mathrm{F} 3 \mathrm{C}$ data for intercomparison.

The daily average temperature profiles from ECMWF were taken at eclipse day (from inside the lunar shadows) and also within the 250-km radius of the F3C GPS RO profiles. For example, Fig. 2(a) shows spatial distribution of the ECMWF grids that are close to within $2250 \mathrm{~km}$ search radius of the 15 Jan 2010 solar eclipse path. However, only those grids in Fig. 2(b) that are within 250-km radius of the eclipse-effect recording RO profiles were selected for analysis. 
Similarly, the daily average temperature profiles were also calculated for the non-eclipse days (from inside the virtual lunar shadows). The daily mean temperature profiles $\left(\overline{T_{k, l}^{\mathrm{ECMWF}}}\right)$ were calculated for each day of the eclipse year and the non-eclipse years as shown in Table 2:

$$
\overline{T_{k, l}^{\mathrm{ECMWF}}}=\frac{\sum_{i=1}^{N} T_{i, k, l}^{\mathrm{ECMWF}}}{N}
$$

Here $N$ represents the total number of the ECMWF grid profiles (shown from a horizontal $2.5^{\circ}$ longitude-latitude grid resolution) that are located within the $250-\mathrm{km}$ radius of each eclipse-recording GPS RO profiles.

Based on these daily average temperature profiles, we can calculate the profiles of difference in daily average temperatures between the eclipse day and each day of the non-eclipse days in the eclipse year and the non-eclipse years, respectively:

$$
\overline{d T_{k}^{\mathrm{ECMWF}}}=\frac{\sum_{l=1}^{L} \overline{T_{k, \text { eclipse day }}^{\mathrm{ECMWF}}}-\overline{T_{k, l}^{\mathrm{ECMWF}}}}{L}
$$

These profiles of daily mean temperature difference are also denoted as $d T$ (ECMWF). Hence,

$$
d T(\mathrm{ECMWF})=\overline{d T_{k}^{\mathrm{ECMWF}}}
$$

\subsection{The Eclipse Tropospheric Cooling and Stratospheric Warming Hypothesis: $d T(\mathrm{~F} 3 \mathrm{C})-d T(\mathrm{ECMWF})$}

Due to the block out of direct solar radiation compared with no block out of solar radiation on the non-eclipse days, $\overline{T_{k, \text { eclipse day }}^{\mathrm{F} C}}$ reduced, and $\overline{T_{k \text {,eclipse day }}^{\mathrm{F} 3 \mathrm{C}}}-\overline{T_{k, l}^{\mathrm{F} 3 \mathrm{C}}}$ becomes more negative. This leads $d T(\mathrm{~F} 3 \mathrm{C})=\overline{d T_{k}^{\mathrm{F} 3 \mathrm{C}}}$ to become more negative. Hence, profiles of temperature differences between the eclipse day and the non-eclipse days in the eclipse years should become more negative than the differences from the non-eclipse years.

The block out effect appears on the F3C data but not fully represented on the operational meteorological analysis data such as ECMWF used here. Hence, the tropospheric cooling hypothesis predicts that in the troposphere of the eclipse years, $d T(\mathrm{ECMWF})$ changes little, while $d T(\mathrm{~F} 3 \mathrm{C})$ becomes more negative. This leads $d T_{\text {eclipse effect }}^{\mathrm{TROO}}=d T(\mathrm{~F} 3 \mathrm{C})-$ $d T$ (ECMWF) to become more negative. In the stratosphere of the eclipse years, $d T$ (ECMWF) changes little, and $d T$ (F3C) becomes more positive (due to the eclipseinduced dynamic warming effect). This leads $d T_{\text {eclipse effect }}^{\mathrm{STRT}}=d T(\mathrm{~F} 3 \mathrm{C})-d T(\mathrm{ECMWF})$ to become more positive.

We expect that (1) profile of temperature differences between the eclipse day and the non-eclipse days in the non-eclipse years should be small for both the eclipse-time average data $(d T(\mathrm{~F} 3 \mathrm{C}))$ and the daily average data $(d T(\mathrm{ECMWF}))$; (2) profiles of temperature differences between the eclipse day and the non-eclipse days in the eclipse years should be large from the eclipse-time average data, due to the eclipse block out effect observed by the F3C; (3) profiles of temperature differences in the eclipse years from F3C should be larger than those from the ECMWF, due to the eclipse effect observed by F3C but not fully expressed in the ECMWF data. 


\section{Results}

\subsection{Spatial Distribution of Eclipse Paths and GPS RO profiles}

Figure 3 shows latitudinal distribution of the GPS RO profiles for the eclipse years and the comparison years (Table 2). These eclipses occurred in latitudes ranging from the NH polar regions, the $\mathrm{NH}$ mid-latitudes, tropical regions of both hemispheres, the $\mathrm{SH}$ mid-latitudes, to the SH high latitudes. Two total eclipses occurred in the NH summer seasons: the 22 July 2009 eclipse over the NH tropics to mid-latitudes (Fig. 3(b)), and the 1 August 2008 eclipse over the NH high to polar latitudes (Fig. 3(a)). The 15 Jan 2010 annular solar eclipse occurred during the $\mathrm{NH}$ winter season, with the GPS RO profiles distributed from the SH tropical region to close to the NH mid-latitudes (Fig. 3(c)). The 22 September 2009 annular solar eclipse occurred during the SH spring season, and in the SH mid-latitudes (Fig. 3(d)). The 22 September 2006 annular solar eclipse occurred in the SH spring season, and in latitudes extend from the NH tropical region to the SH high latitudes (Fig. 3(e)).

Figure 4 shows mean temperature profiles for the eclipse day and the non-eclipse days of each eclipse event. These profiles are shown following the occurrence of the eclipse latitudes from the NH polar to high latitudes (Fig. 4(a)), the NH mid-latitudes to the SH tropical latitudes (Fig. 4(b)), the SH mid to high latitudes (Fig. 4(c)), to the NH tropical latitudes to the SH high latitudes (Fig. 4(d)). We can clearly see the different tropopause height at high and low latitudes, varying between 11-km altitudes over the high latitudes and 17-19 km over the low latitudes.

\subsection{The NH Polar to High Latitudes Eclipse: 1 August 2008}

Figure 5(a) compares mean temperature differences during the eclipse occurred on 1 August 2008, and those mean temperature differences from the non-eclipse years. The eclipse-time mean temperature differences $(d T(\mathrm{~F} 3 \mathrm{C}))$ show pronounced negative values in the troposphere (4-10 km altitudes), and positive values in the stratosphere (10-16 km altitudes). This is a clear indication of eclipse-induced cooling in the troposphere and warming in the lower stratosphere. These results are consistent with what we observed in Wang and Liu (2010).

Figure 5(a) shows that daily mean temperature differences (dT(ECMWF)) in the troposphere (below 8-km altitude) were positive, indicating that temperatures in the troposphere during the post-eclipse period (2-11 August) are generally warmer than temperature on the eclipse day (1 August) and in pre-eclipse days (22-31). This feature also appear in the noneclipse years of 2007 and 2009 (Fig. 5(b)). Hence, the daily mean temperature differences are predominantly positive for these 3 years based on the ECMWF analysis.

For the non-eclipse years, Fig. 5(b) shows strong positive temperature differences from the eclipse-time means, and these values are larger than those from the daily means. Positive temperature differences appear in the troposphere, and these values are larger than the daily means. Hence, the non-eclipse years show that eclipse-time mean temperature differences are much warmer than the daily mean temperature differences. This indicates more warming of the troposphere in post-eclipse periods than the pre-eclipse periods. This feature also reveals that the cooling in the troposphere during the eclipse year of 2008 is indeed caused by the eclipse effect, as mean temperature differences $(d T(\mathrm{~F} 3 \mathrm{C})-d T(\mathrm{ECMWF}))$ in the troposphere are distinctively negative compared with the predominantly positive values from the other two non-eclipse years. 
Fig. 3 Latitudinal distribution of F3C GPS RO profiles for (a) 1 August 2008, (b) 22 July 2009, (c) 15 January 2010,

(d) 26 January 2009, and

(e) 22 September 2006 eclipse cases. Solid lines indicate GPS RO profile counts in the eclipse years, while the dashed lined indicate GPS RO counts in the comparison years

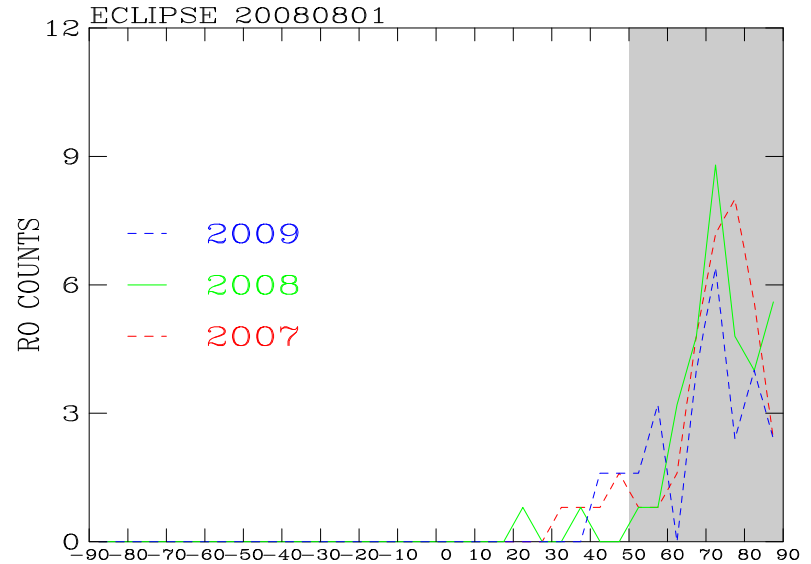

(a)

\section{LATITUDE}

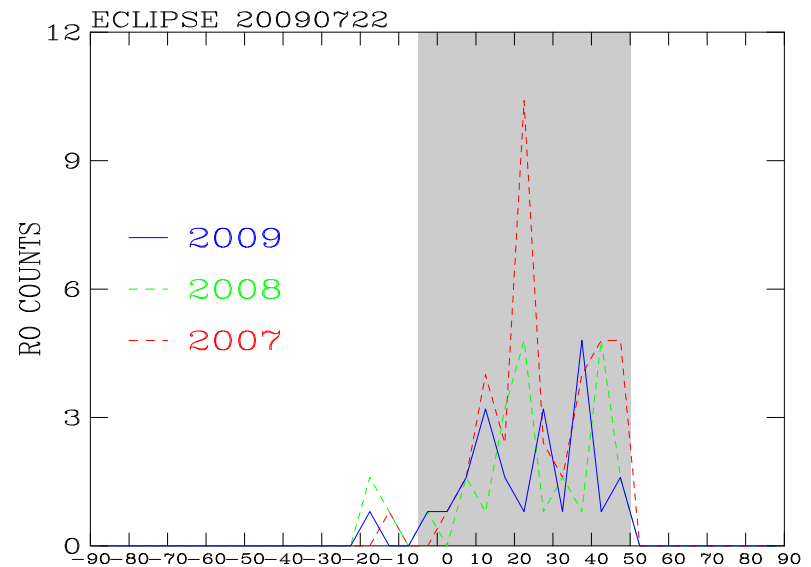

(b)
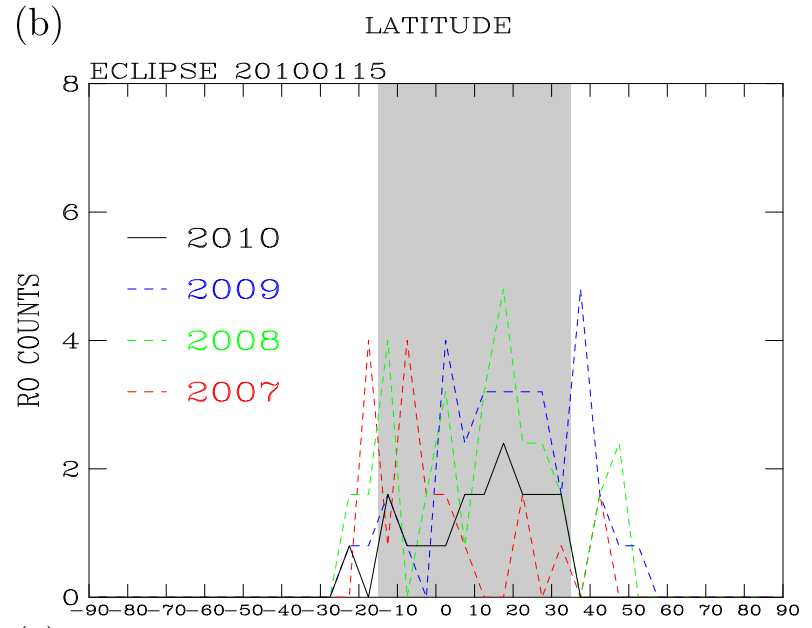

(c) 
Fig. 3 (Continued)
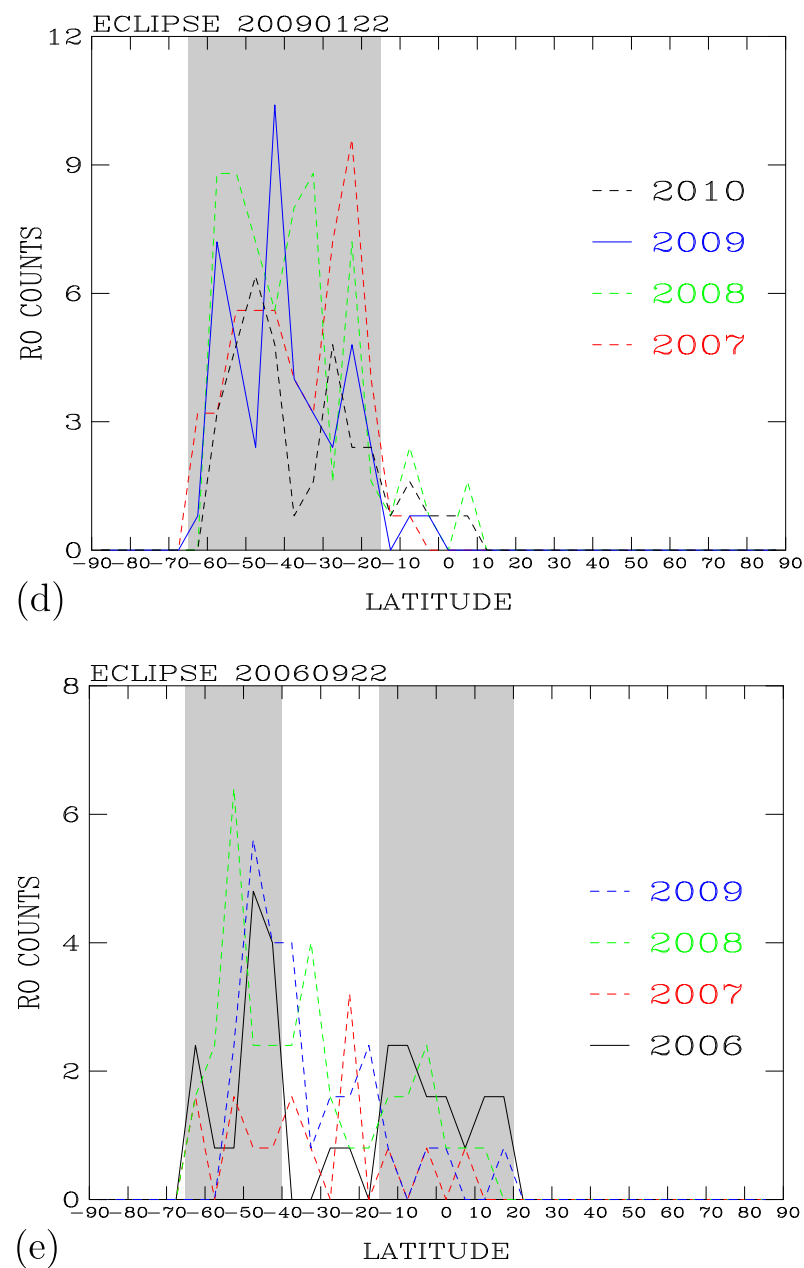

\subsection{The NH Mid to the SH Tropical Latitudes Eclipse: 22 July 2009}

Figure 6(a) compares average of profiles of temperature differences between the eclipse day (22 July) and the non-eclipse days (12-21 July, and 23 July-1 August) in 2009. The daily average profiles of temperature differences ( $d T(\mathrm{ECMWF}))$ show negative daily mean temperature differences of about $-1^{\circ} \mathrm{C}$ exist throughout the troposphere (below $10 \mathrm{~km}$ altitude), while positive daily mean temperature differences of up to $3^{\circ} \mathrm{C}$ appear in the stratospheric region of 12 to $30 \mathrm{~km}$. The eclipse-time mean temperature differences $(d T(\mathrm{~F} 3 \mathrm{C}))$ shows similar pattern compared with the daily mean temperature differences, but with a large negative mean eclipse-time temperature differences of $-2^{\circ} \mathrm{C}$ at altitudes below $10 \mathrm{~km}$ altitudes and positive eclipse-time mean temperature differences of up to $6^{\circ} \mathrm{C}$ in the stratospheric region of 12 to $30 \mathrm{~km}$.

Hence, the mean temperature differences $(d T(\mathrm{~F} 3 \mathrm{C})-d T(\mathrm{ECMWF}))$ on the eclipse day of $22 \mathrm{Jul} 2009$ are about $1{ }^{\circ} \mathrm{C}$ cooler in the troposphere, and about $0-3^{\circ} \mathrm{C}$ warmer in the lower stratosphere than those daily mean temperature differences of the non-eclipse days of 12-21 July 2009 and 23 July-1 August 2009. The warming in the stratosphere occurred in 


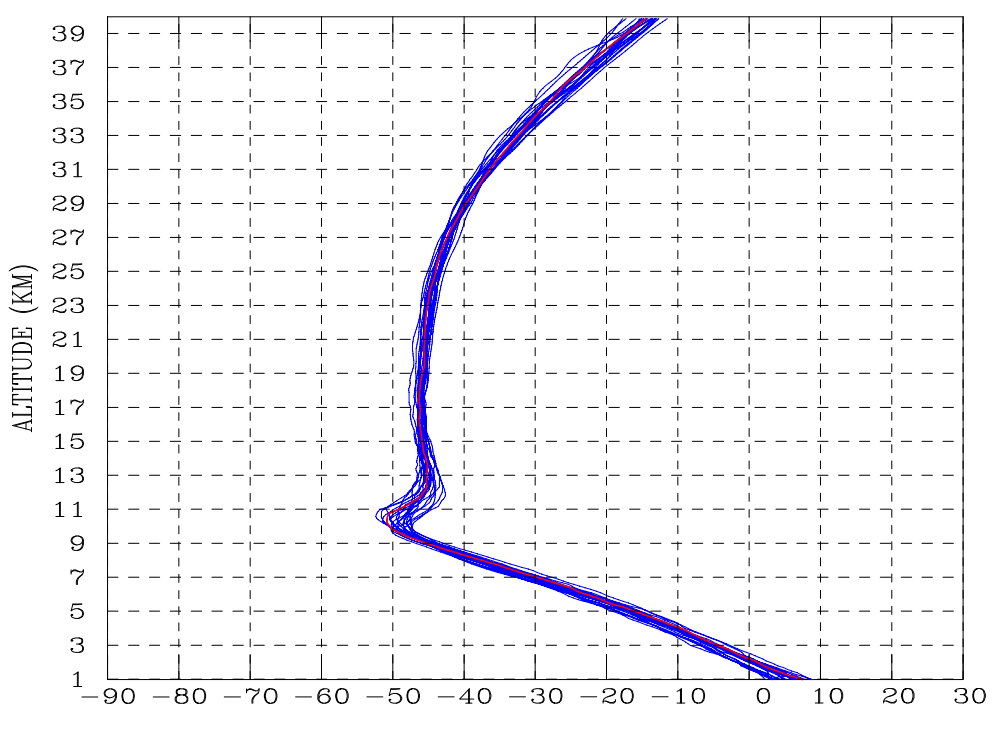

TEMPERATURE (C)

(a) The 200808 T. Eclipse

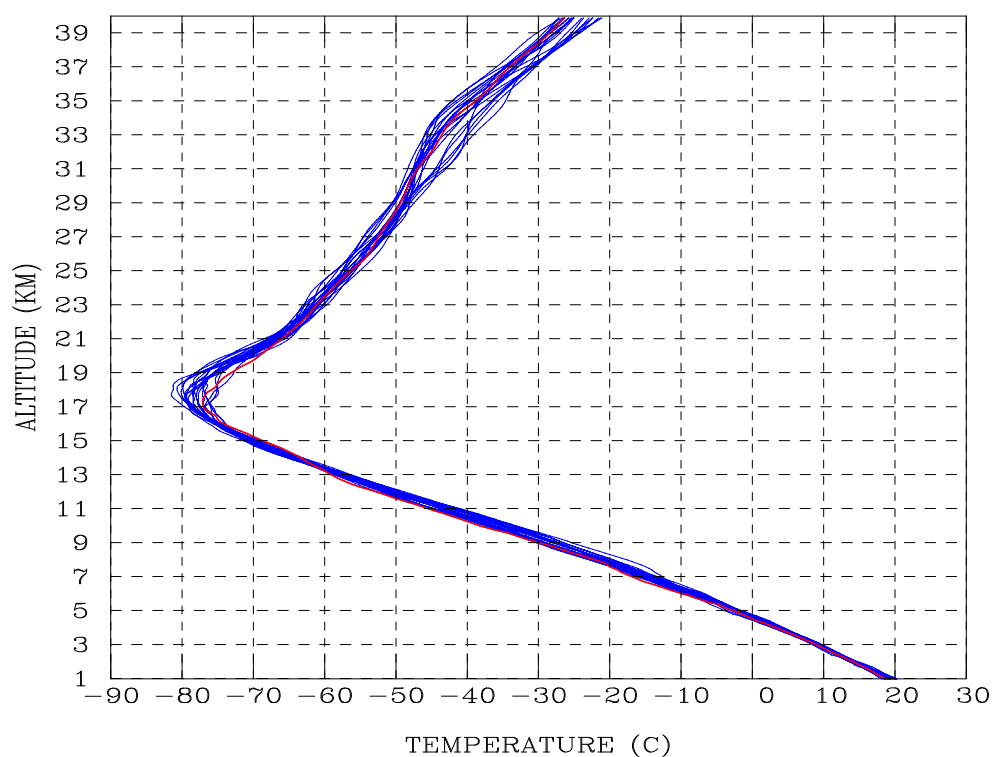

(b) The 201001 A. Eclipse

Fig. 4 Profiles of temperatures from F3C for the (a) 1 August 2008, (b) 15 January 2010, (c) 26 January 2009 , and (d) 22 September 2006 (occurred between $20^{\circ} \mathrm{N}-15^{\circ} \mathrm{S}$ ) eclipses. Red curves indicate temperature profile occurred in the eclipse days, while blue curves indicates temperature profiles occurred 10-day before and after the eclipse day of each event 


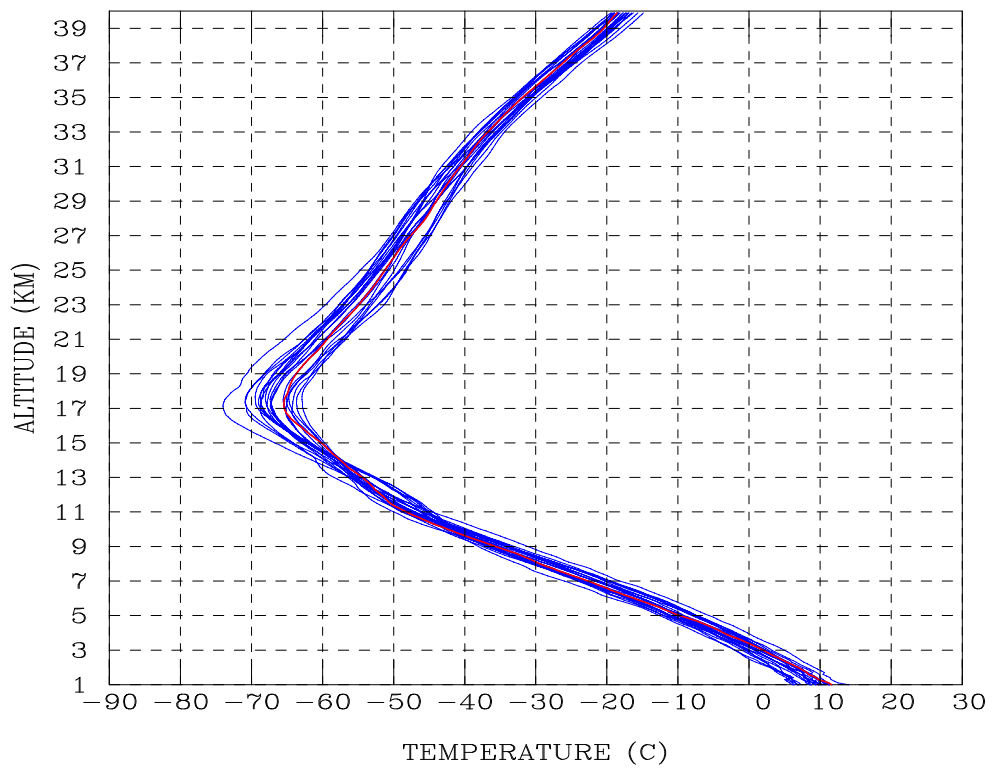

(c) The 200901 A. Eclipse

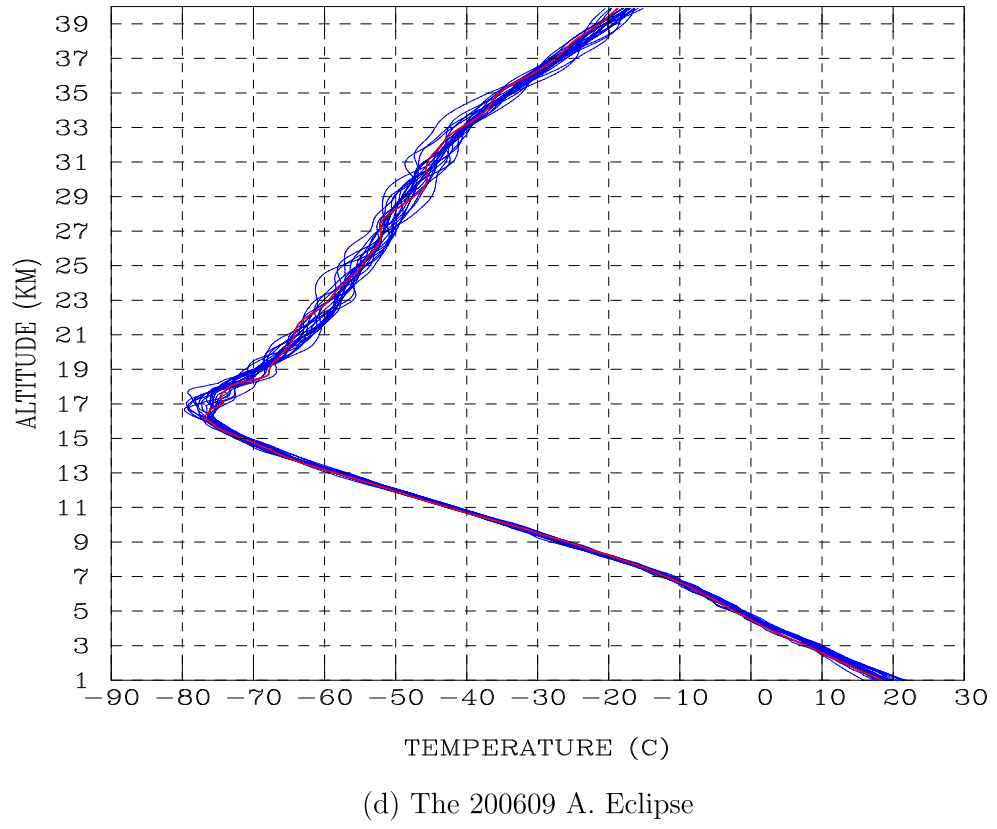

Fig. 4 (Continued)

the regions between 13 and $22 \mathrm{~km}$ altitudes, with a peak of $3^{\circ} \mathrm{C}$ warming centered around $17 \mathrm{~km}$ altitude.

Figure 6(b) compares mean profiles of temperature differences occurred in the same period but for non-eclipse years of 2007 and 2008. The calculations show that the mean 


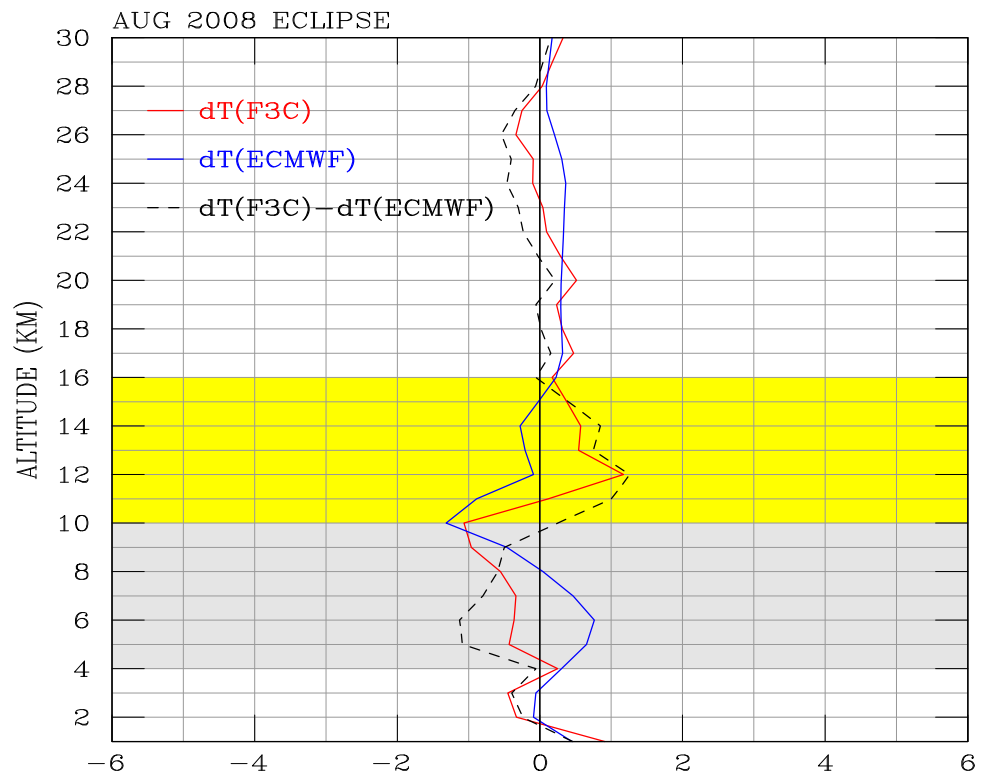

(a)

TEMPERATURE（C)

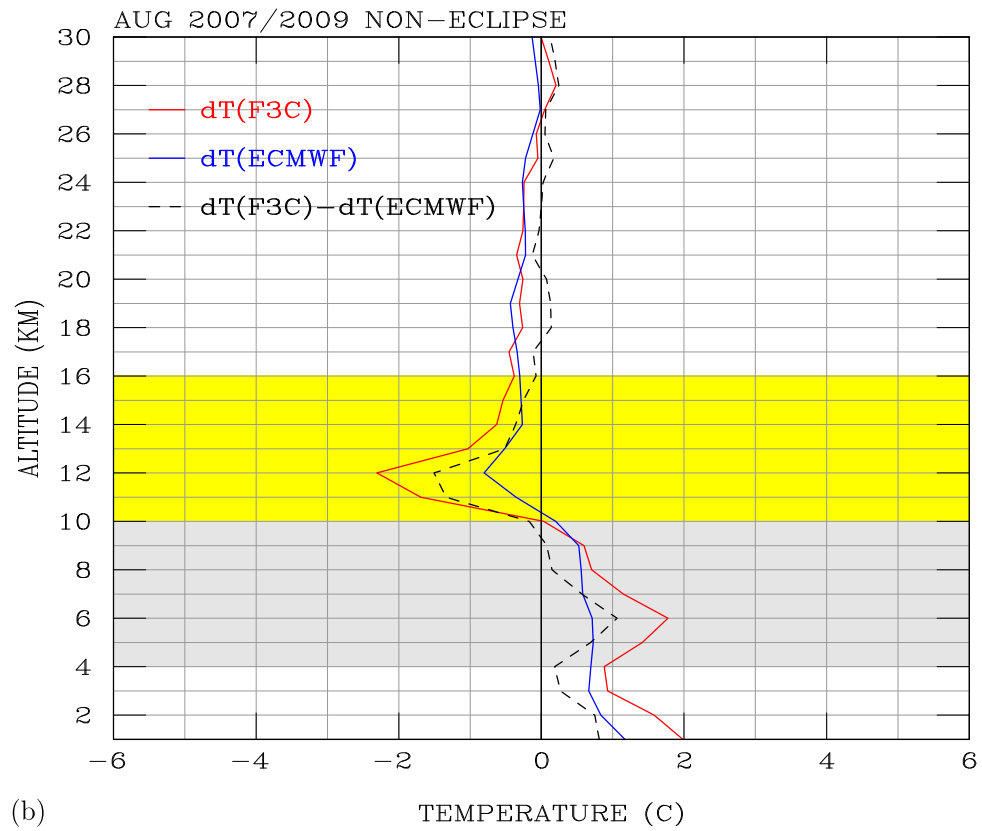

Fig. 5 (a) The 1 August 2008 total solar eclipse. Mean profiles of temperature differences between eclipse and non-eclipse days from F3C (red curves) and ECMWF (blue curves), respectively; and the difference of mean profiles between F3C and ECMWF (black dashed curves). (b) Average results from the non-eclipse years of 2007 and 2009 

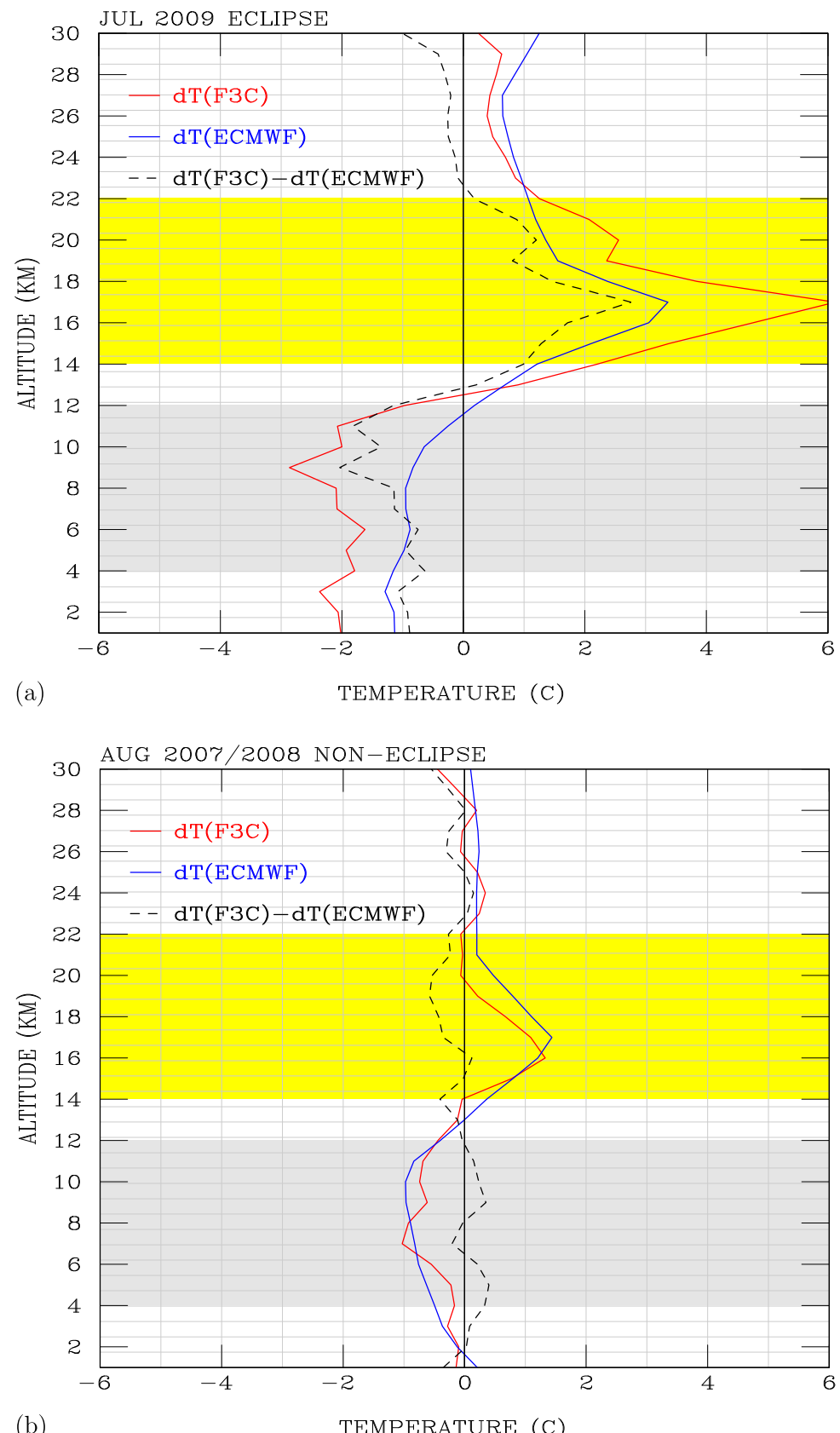

Fig. 6 (a) The 22 July 2009 total solar eclipse. Mean profiles of temperature differences between eclipse and non-eclipse days from F3C (red curves) and ECMWF (blue curves), respectively; and the difference of mean profiles between F3C and ECMWF (black dashed curves). (b) Average results from the non-eclipse years of 2007 and 2008 
eclipse-time temperature differences and the mean daily temperature differences are very close to each other. The difference between the mean eclipse-time profiles and the mean daily profiles $(d T(\mathrm{~F} 3 \mathrm{C})-d T(\mathrm{ECMWF}))$ are small, within 0.5 and $-0.5^{\circ} \mathrm{C}$ through most of the troposphere and the stratosphere.

Figures 6(b) demonstrates that the temperature differences from the eclipse-time means are close to the daily means in the troposphere. These results validate our hypothesis shown in Sect. 2.4, that the eclipse-time mean temperatures are generally similar to the daily mean temperatures in the non-eclipse years of 2007 and 2008. When compared with these two non-eclipse years, the eclipse year of 2009 show very distinctive cooling in the troposphere and warming in the middle to lower stratosphere.

Hence, we further prove that the 22 July 2009 eclipse do indeed produced significant cooling in the troposphere and warming in the lower stratosphere when compared with the non-eclipse years. The results shown here are consistent with those reported in Wang and Liu (2010).

\subsection{The NH Sub-tropical to the SH Tropical Latitudes Eclipse: 15 January 2010}

Figure 7(a) shows comparison of mean profiles of temperature differences during the 15 January 2010 annular solar eclipse. The mean daily temperature differences ( $d T$ (ECMWF)) are negative in the troposphere and positive in the lower stratosphere. The mean eclipse-time temperature differences $(d T(\mathrm{~F} 3 \mathrm{C}))$ show similar pattern to those of mean daily temperature differences. However, the mean temperature differences $(d T(\mathrm{~F} 3 \mathrm{C})-d T(\mathrm{ECMWF}))$ are more negative in the troposphere and more positive in the stratosphere than the mean daily temperature differences. This elevated cooling in the troposphere and warming in the stratosphere (as shown in $d T(\mathrm{~F} 3 \mathrm{C})-d T(\mathrm{ECMWF})$ ) indicates the effect of the eclipse. These results are consistent with those shown during the 22 July 2009 total solar eclipse (Fig. 6(a)), and the 1 August 2008 total solar eclipse (Fig. 5(a)).

Further comparisons were made to compare mean temperature differences between the daily and the eclipse-time values following the 15 January 2010 eclipse path but in the noneclipse year of 2007, 2008, and 2009. For comparisons in these non-eclipse years (Fig. 7(b)), we find that mean temperature differences $(d T(\mathrm{~F} 3 \mathrm{C})-d T(\mathrm{ECMWF}))$ in the troposphere and the lower stratosphere are small compared with those shown in the eclipse year. These comparisons again demonstrate the eclipse effect. We note that the wavy structure of temperature differences occurs in the stratosphere looks like gravity waves. This will require further study to demonstrate the vertical propagating gravity waves associated with this case.

\subsection{The SH Mid to High Latitudes Eclipse: 26 January 2009}

Figure 8(a) compares mean temperature differences between the eclipse-time and the daily mean values during the annular solar eclipse that had occurred on 26 January 2009, and those occurred in the non-eclipse years of 2007, 2008, and 2010 (Fig. 8(db)). For the mean temperature differences in the eclipse year of 2009, eclipse-time mean temperature differences show clear cooling in the middle to upper troposphere and warming in the lower stratosphere (14-22 km altitudes, Fig. 8(a)). The daily average mean temperature differences show only clear cooling in the upper troposphere (10-12 km altitudes) and moderate warming in the stratosphere. As such, the mean temperature differences $(d T(\mathrm{~F} 3 \mathrm{C})-d T(\mathrm{ECMWF}))$ are negative in the troposphere and positive in the lower stratosphere. These results are consistent with the pattern of the eclipse-induced tropospheric cooling and stratospheric warming shown during the 22 July 2009 total solar eclipse. 


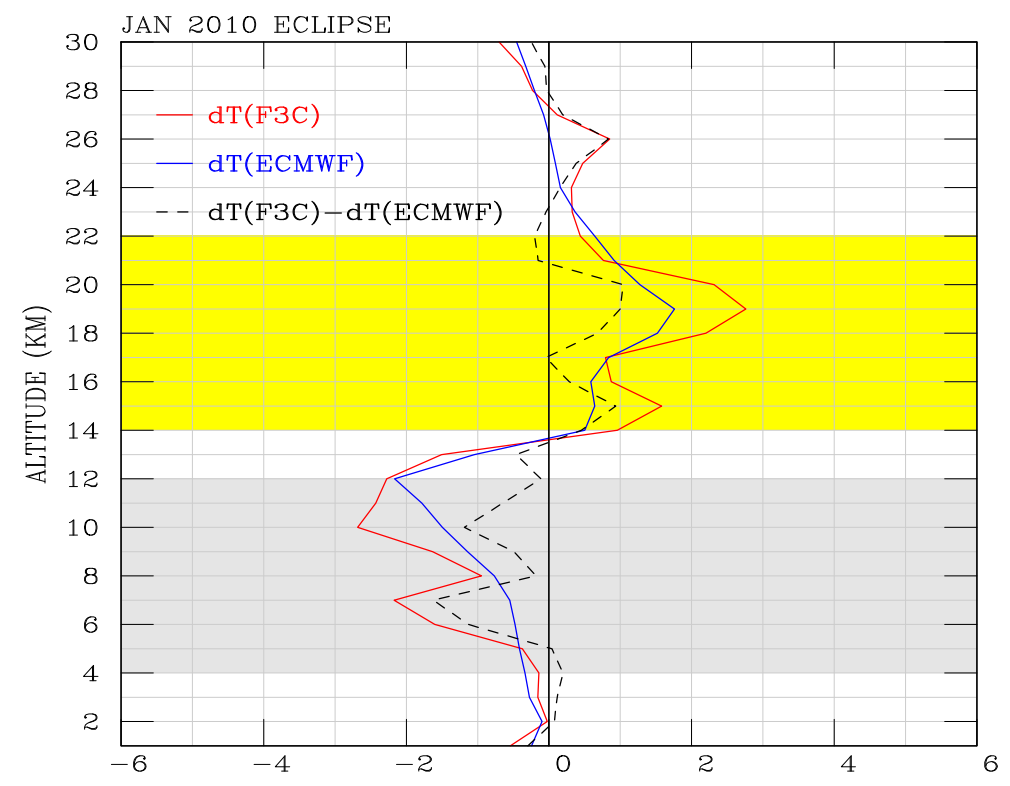

(a)

TEMPERATURE（C)

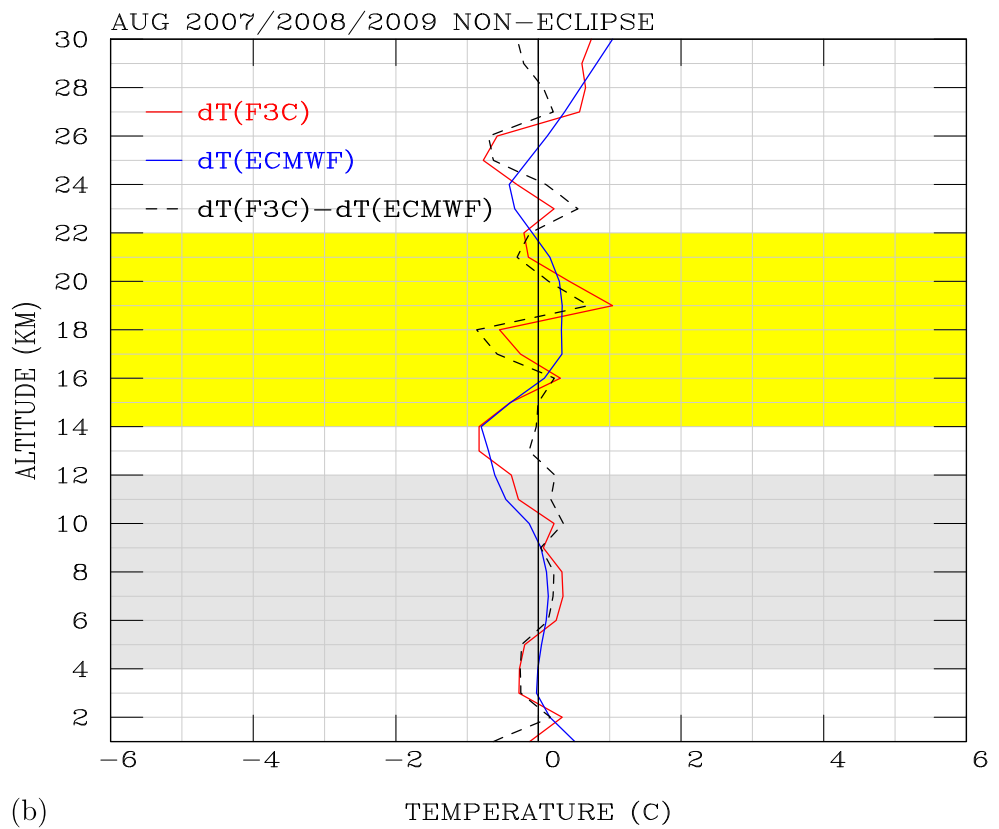

Fig. 7 (a) The 15 January 2010 annular solar eclipse. Red curves show mean profiles of temperature differences between eclipse and non-eclipse days from F3C. Mean temperature differences from ECMWF are shown in blue curves. The difference of mean profiles between F3C and ECMWF are shown in black dashed curves. (b) Average results from the non-eclipse years of 2007, 2008, and 2009 


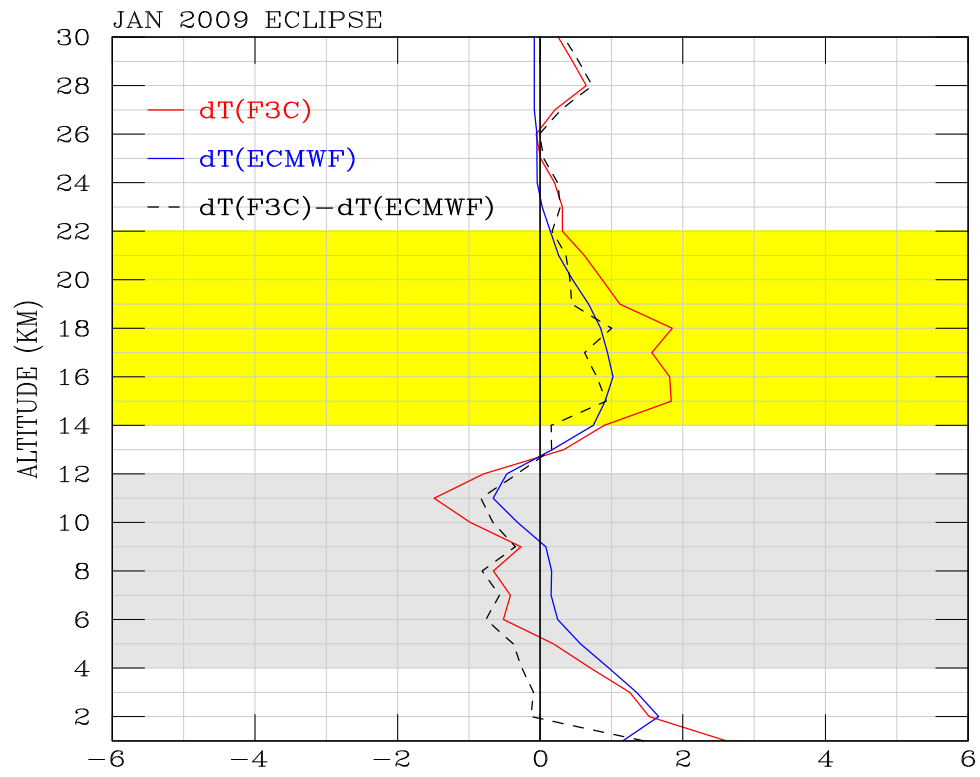

(a)

TEMPERATURE (C)

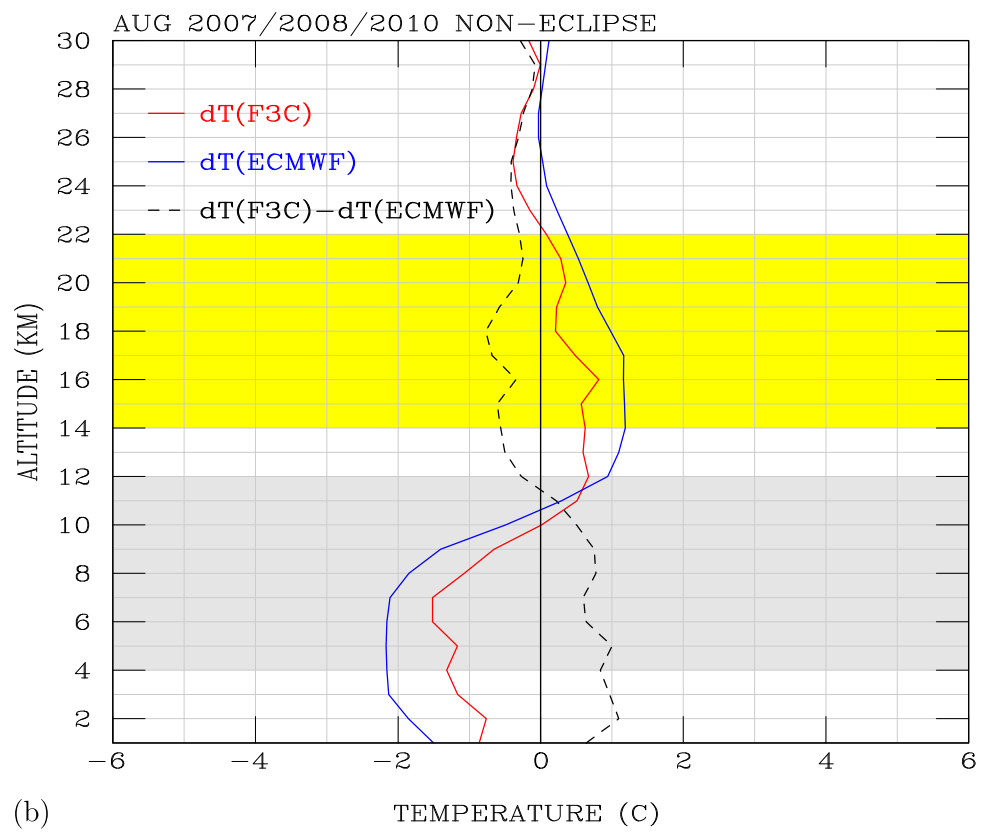

Fig. 8 (a) The 26 January 2009 annular solar eclipse. Mean profiles of temperature differences between eclipse and non-eclipse days from $\mathrm{F} 3 \mathrm{C}$ are shown in red curves and from ECMWF are shown in blue curves. The difference of mean profiles between F3C and ECMWF are shown in black dashed curves. (b) Average results from the non-eclipse years of 2007, 2008, and 2010 
The non-eclipse years (Fig. 8(b)) show more negative mean temperature differences in the troposphere and more positive mean temperature differences in the lower stratosphere from the daily average values than from the eclipse-time average values. This results in the warming effect in the eclipse-time troposphere and cooling effect in the eclipse-time lower stratosphere.

The 26 January 2009 eclipse tracked a path that mostly remains in the summer of the South Hemisphere. The predominantly negative daily mean temperature differences in the troposphere of the non-eclipse years of 2007, 2008, and 2010 clearly indicate that the temperatures during the post-eclipse days (27 January-5 February) are warmer than the eclipse (26 January) and the pre-eclipse days (16-25 January).

Note that the pattern of eclipse-time warming in the troposphere and cooling in the lower stratosphere seen from the non-eclipse years are completely opposite to the eclipse-induced pattern of the eclipse-time cooling in the troposphere and warming in the stratosphere.

\subsection{The SH High to the NH Tropical Latitudes Eclipse: 22 September 2006}

For the annular solar eclipse event occurred on 22 September 2006, the F3C RO profiles mainly concentrates on two latitudinal bands: mid to high latitudes, between $40^{\circ}$ and $65^{\circ} \mathrm{S}$; and tropical latitudes, between $20^{\circ} \mathrm{N}$ and $15^{\circ} \mathrm{S}$. For the RO profiles in the mid to high latitudes $\left(40^{\circ}\right.$ to $\left.65^{\circ} \mathrm{S}\right)$, we find they exhibit strong year to year variability (not shown here). This may be due to the presence of the Antarctic polar vortex during this time of the year. Here we analyze profiles of temperature differences in the lower latitudes.

Figure 9 compares profiles of mean temperature differences $(d T(\mathrm{~F} 3 \mathrm{C})-d T(\mathrm{ECMWF}))$ between the eclipse and the non-eclipse days on the latitudes in the tropical latitudes. In the lower troposphere (below 6-km altitude), the general cooling from the eclipse year in 2006 (Fig. 9(a)) is more pronounced than the minor warming from the non-eclipse years of 2007, 2008, and 2009 (Fig. 9(b)). This characteristic cooling in the lower troposphere is consistent with those shown previously. However, the warming in the lower stratosphere in the 2006 eclipse year is less clear when compared with other non-eclipse years. It may be the cooling in the troposphere is not strong enough to induce dynamically and adiabatically warming from downward motions.

\subsection{Verification of the Eclipse Tropospheric Cooling and Stratospheric Warming Hypothesis}

Table 3 summarizes mean profiles of changes of temperature $(d T(\mathrm{~F} 3 \mathrm{C})-d T(\mathrm{ECMWF}))$ in the 4-10 km troposphere and the 14-20 km stratosphere for the five solar eclipses analyzed in this work. Except for the 22 September 2006 annular solar eclipse, all the other four eclipses show a distinctive hallmark of the atmospheric response to major solar eclipses.

For these four eclipses in the troposphere, the values of $d T$ (F3C) $-d T$ (ECMWF) are consistently negative, with values varying between -0.6 and $-1.2^{\circ} \mathrm{C}$ for the eclipse years. On the contrary, the non-eclipse comparing years show that the values of $d T(\mathrm{~F} 3 \mathrm{C})-$ $d T(\mathrm{ECMWF})$ are either greater or equal to zero. The value of $d T(\mathrm{~F} 3 \mathrm{C})-d T(\mathrm{ECMWF})$ in the troposphere for 2006 is zero, which is still lower than those of the non-eclipse years. This is consistent with the eclipse cooling in the troposphere. In the stratosphere of these four eclipses, the values of $d T(\mathrm{~F} 3 \mathrm{C})-d T(\mathrm{ECMWF})$ are consistently positive, with values varying between 0.4 and $1.3^{\circ} \mathrm{C}$. The values of $d T(\mathrm{~F} 3 \mathrm{C})-d T$ (ECMWF) are mostly negative, three positive values, and one zero for other non-eclipse comparing years.

For a total of five eclipse cases shown in Table 3, four cases show tropospheric cooling and stratospheric warming results while one case (22 September 2006) does not show this 


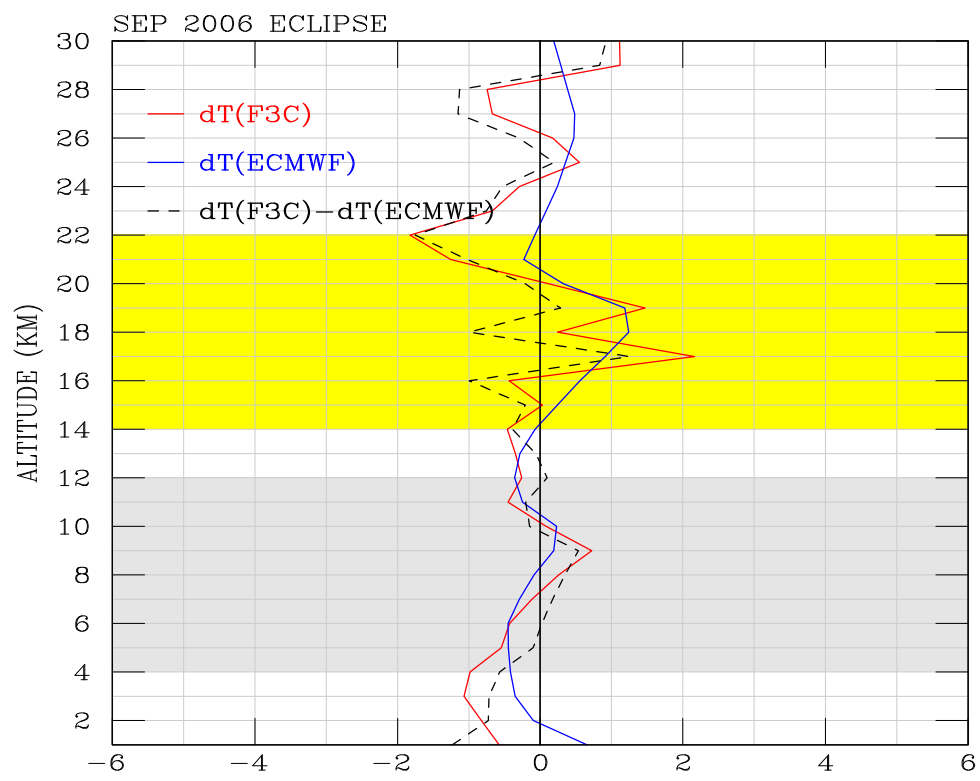

(a)

TEMPERATURE (C)

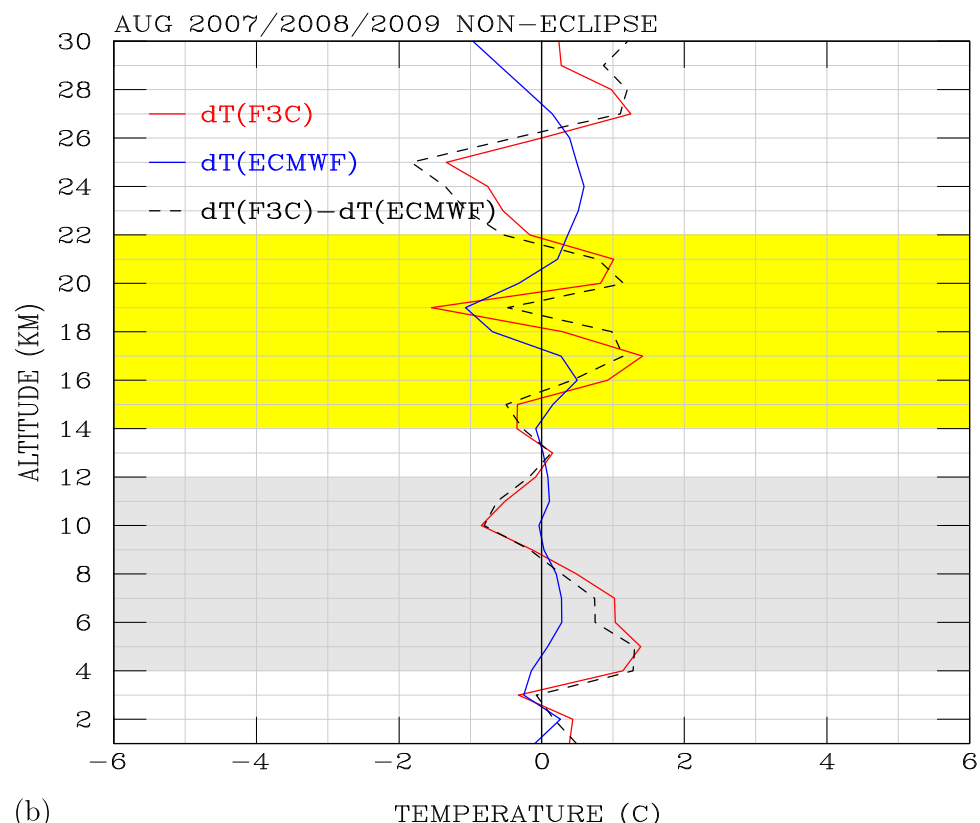

Fig. 9 (a) The 22 September 2006 annular solar eclipse. Mean profiles of temperature differences between eclipse and non-eclipse days from F3C (red curves) and ECMWF (blue curves), respectively; and the difference of mean profiles between $\mathrm{F} 3 \mathrm{C}$ and ECMWF (black dashed curves). (b) Average results from the non-eclipse years of 2007, 2008, and 2009. These analysis are based on GPS and ECMWF profiles occurred between $20^{\circ} \mathrm{N}$ and $15^{\circ} \mathrm{S}$ 
Table 3 Mean temperature differences $(d T(\mathrm{~F} 3 \mathrm{C})-d T(\mathrm{ECMWF}))$ for the eclipse and non-eclipse cases

\begin{tabular}{|c|c|c|c|c|}
\hline $\begin{array}{l}\text { Latitudinal } \\
\text { Extent }\end{array}$ & Eclipse events & $\begin{array}{l}\text { Comparison } \\
\text { Years }\end{array}$ & $\begin{array}{l}\text { Strato- } \\
\text { sphere }\end{array}$ & $\begin{array}{l}\text { Tropo- } \\
\text { sphere }\end{array}$ \\
\hline \multirow[t]{2}{*}{ NH high latitudes } & \multirow[t]{2}{*}{1 Aug $2008^{a}$} & & 0.6 & -0.6 \\
\hline & & 2009 & -0.7 & 0.7 \\
\hline$\delta T=1: 55$ & & 2007 & -0.5 & 0.0 \\
\hline \multirow[t]{2}{*}{ NH mid latitudes } & \multirow[t]{2}{*}{$22 \mathrm{Jul} 2009^{\mathrm{b}}$} & & 1.3 & -1.2 \\
\hline & & 2008 & 0.1 & 0.1 \\
\hline$\delta T=3: 24$ & & 2007 & -0.7 & 0.2 \\
\hline \multirow[t]{2}{*}{ NH low lat.-SH tropics } & \multirow[t]{2}{*}{15 Jan $2010^{\mathrm{b}}$} & & 0.4 & -0.6 \\
\hline & & 2009 & -0.4 & 0.3 \\
\hline \multirow[t]{2}{*}{$\delta T=3: 36$} & & 2008 & -0.2 & 0.0 \\
\hline & & 2007 & 0.3 & -0.1 \\
\hline \multirow[t]{2}{*}{ SH mid latitudes } & \multirow[t]{4}{*}{26 Jan $2009^{b}$} & & 0.5 & -0.5 \\
\hline & & 2010 & -1.0 & 1.1 \\
\hline \multirow[t]{2}{*}{$\delta T=3: 43$} & & 2008 & -0.5 & 0.5 \\
\hline & & 2007 & 0.0 & 0.0 \\
\hline \multirow[t]{2}{*}{ NH tropics.-SH mid-high lat. } & \multirow[t]{4}{*}{$22 \operatorname{Sep} 2006^{b}$} & & -0.4 & 0.0 \\
\hline & & 2009 & 0.6 & 0.7 \\
\hline \multirow[t]{2}{*}{$\delta T=3: 35$} & & 2008 & 0.2 & 0.5 \\
\hline & & 2007 & 0.1 & 0.0 \\
\hline
\end{tabular}

${ }^{\text {a }}$ The tropospheric mean is calculated for the $4-10 \mathrm{~km}$ altitudes, while the stratospheric mean is calculated for the $10-16 \mathrm{~km}$ altitudes

${ }^{\mathrm{b}}$ The tropospheric mean is calculated for the $4-12 \mathrm{~km}$ altitudes, while the stratospheric mean is calculated for the 14-22 km altitudes

$\delta T$ : Eclipse duration

characteristic. For a total of thirteen non-eclipse comparison cases shown in Table 3, one case (the 2009 comparison year for the 15 January 2010 eclipse) shows tropospheric cooling and stratospheric warming results, while the rest of the twelve cases do not show this characteristic. A test of statistical significance shows that if the null hypothesis $\left(H_{0}=\right.$ there is no relationship between the coupled troposphere-cooling-stratosphere-warming events and the eclipses) is true, then the probability of getting four coupled troposphere-coolingstratosphere-warming events out of the five eclipse cases is very small ( $P=0.002$, ChiSquare Test) (More 2001). These results show that our hypothesis is statistically significant. The cooling of the troposphere and the warming of the stratosphere is a predictable response of the atmosphere to the major solar eclipse.

\section{Summary}

The block out of short wave solar radiation by major eclipse events provides great opportunities to study the coupling between the troposphere and the stratosphere. In this work we used the $\mathrm{F} 3 \mathrm{C}$ RO profiles to obtain temperature profiles inside the lunar shadow, and the ECMWF analysis to obtain background non-eclipse temperature profiles. The eclipse effects were calculated based on the difference of F3C and ECMWF profiles. We have analyzed five eclipse cases, and thirteen non-eclipse comparison cases. Our results show -0.6 to $-1.2^{\circ} \mathrm{C}$ 
cooling in the troposphere and 0.4 to $1.3^{\circ} \mathrm{C}$ warming in the middle to lower stratosphere during the eclipses. These results are statistically significant $(P=0.002$ with a Chi-Square Test).

In this work we showed that the direct cooling in troposphere and induced warming in the middle to lower stratosphere occurs during the major solar eclipses. The mechanism for the cooling in the troposphere is thermally driven while the warming in the stratosphere is dynamically controlled. As discussed in Wang and Liu (2010), the cooling produces contraction of air in the troposphere, which induces downward movement in the middle to lower stratosphere. The downward motion adiabatically heats the middle to lower stratosphere, resulting in the warming in that region.

Our analyses of the stratosphere-troposphere coupling during the 2006-2010 major solar eclipses shows that the troposphere is the region in the atmosphere that responses quickly to the shield of solar radiation. This direct thermal effect in the troposphere then propagates upward through the stratosphere-troposphere coupling into the stratosphere, which not only responses to the shield of solar radiation but also to the dynamic forcing from below. The resulting warming indicates that dynamically driven warming dominates over the thermally cooling in the middle to lower stratosphere.

Acknowledgements We thank NSPO for providing F3C data, NASA for the eclipse path coordinates (eclipse predictions by Fred Espenak at NASA's GSFC), and discussions with the GPSARC team in Taiwan. We are very grateful to the anonymous reviewer for insightful comments that greatly improved the clarity of this paper. We are also very grateful to Rudolf Treumann for inviting us to present this work in the ISSI-Coupling 2010 workshop in Bern, Switzerland. This work is supported by NSPO-S-099010(E), NSPOS-100011, and NSC-100-2119-M-008-020.

Open Access This article is distributed under the terms of the Creative Commons Attribution Noncommercial License which permits any noncommercial use, distribution, and reproduction in any medium, provided the original author(s) and source are credited.

\section{References}

R.C. Anderson, D.R. Keefer, O.E. Myers, Atmospheric pressure and temperature changes during the 7 March 1970 solar eclipse. J. Atmos. Sci. 29, 583-587 (1972)

R. Anthes et al., The COSMIC/FORMOSAT-3 mission: early results. Bull. Am. Meteorol. Soc. 89, 313-333 (2008)

H.N. Ballard, R. Valenzuela, M. Izquierdo, J.S. Randhawa, R. Morla, J.F. Bettle, Solar eclipse: temperature, wind, and ozone in the stratosphere. J. Geophys. Res. 74, 711-712 (1969)

R. Buizza, P.L. Houtekamer, G. Pellerin, Z. Toth, Y. Zhu, M. Wei, A comparison of the ECMWF, MSC, and NCEP global ensemble prediction systems. Mon. Weather Rev. 133, 1076-1097 (2005)

G. Chimonas, Internal gravity-wave motions induced in the Earth's atmosphere by a solar eclipse. J. Geophys. Res. 75, 5545-5551 (1970)

G. Chimonas, C.O. Hines, Atmospheric gravity waves induced by a solar eclipse 2. J. Geophys. Res. 76, 7003-7005 (1971)

F. Espenak, J. Anderson, Total solar eclipse of 2009 July 22. NASA/TP-2008-214169 (2008)

F. Espenak, J. Meeus, Five Milliennium canon of solar eclipses: -1999 to +3000 (2000 BCE to $3000 \mathrm{CE})$. NASA/TP-2006-214141 (2006)

D. Founda et al., The effect of the total solar eclipse of 29 March 2006 on meteorological variables in Greece. Atmos. Chem. Phys. 7, 5543-5553 (2007)

E. Gerasopoulos et al., The total solar eclipse of March 2006: overview. Atmos. Chem. Phys. 7, 5205-5220 (2007)

G.A. Hajj et al., CHAMP and SAC-C atmospheric occultation results and intercomparisons. J. Geophys. Res. 109, D06109 (2004). doi:10.1029/2003JD003909

J.R. Holton, P.H. Haynes, M.E. McIntyre, A.R. Douglass, R.B. Rood, L. Pfister, Stratosphere-troposphere exchange. Rev. Geophys. Space Phys. 33, 403-439 (1995) 
T. Kameda, K. Fujita, O. Sugita, N. Hirasawa, S. Takahashi, Total solar eclipse over Antarctica on 23 November 2003 and its effects on the atmosphere and snow near the ice sheet surface at Dome Fuji. J. Geophys. Res. 114, D18115 (2009). doi:10.1029/2009JD011886

Y.-H. Kuo, W.S. Schreiner, J. Wang, D.L. Rossiter, Y. Zhang, Comparison of GPS radio occultation soundings with radiosondes. Geophys. Res. Lett. 32, L05817 (2005). doi:10.1029/2004GL021443

E.R. Kursinski, G.A. Hajj, J.T. Schofield, R.P. Linfield, K.R. Hardy, Observing Earth's atmosphere with radio occultation measurements using the Global Positioning System. J. Geophys. Res. 102(D19), 2342923465 (1997)

H. Le, L. Liu, X. Yue, W. Wan, B. Ning, Latitudinal dependence of the ionospheric response to solar eclipses. J. Geophys. Res. 114, A07308 (2009). doi:10.1029/2009JA014072

C. Lindsey et al., Extreme-infrared brightness profile of the solar chromospheres obtained during the total eclipse of 1991. Nature 358, 308-310 (1992)

D.S. More, Statistics: Concepts and Controversies, 5th edn. (Freeman, New York, 2001), p. 557

J.M. Pasachoff, Solar eclipses as an astrophysical laboratory. Nature 459, 789-795 (2009)

T. Schmidt, J. Wickert, A. Haser, Variability of the upper troposphere and lower stratosphere observed with GPS radio occultation bending angles and temperatures. Adv. Space Res. 46, 150-161 (2010)

E.J. Seykora, A. Bhatnagar, R.M. Jain, J.L. Streete, Evidence of atmospheric gravity waves produced during the 11 June 1983 total solar eclipse. Nature 313, 124-125 (1985)

M.G. Shepherd, T. Tsuda, Large-scale planetary disturbances in stratospheric temperature at high-latitudes in the southern summer hemisphere. Atmos. Chem. Phys. 8, 7557-7570 (2008)

R.A. Treumann, Z. Klos, M. Parrot, Physics of electric discharges in atmospheric gases: An informal introduction. Space Sci. Rev. 137, 133-148 (2008)

K.-Y. Wang, Profiles of the atmospheric temperature response to the Saharan dust outbreaks derived from FORMOSAT-3/COSMIC and OMI AI. Atmos. Res. 96, 110-121 (2010)

K.-Y. Wang, S.-C. Lin, First continuous GPS soundings of temperature structure over Antarctic winter from FORMOSAT-3/COSMIC constellation. Geophys. Res. Lett. 34, L12805 (2007). doi:10.1029/2007GL030159

K.-Y. Wang, C.-H. Liu, Profiles of temperature responses to the 22 July 2009 total solar eclipse from FORMOSAT-3/COSMIC constellation. Geophys. Res. Lett. 37, L01804 (2010). doi:10.1029/2009GL040968

K.-Y. Wang, S.-C. Lin, L.-C. Lee, Immediate impact of the Mt. Chaiten eruption on atmosphere from FORMOSAT-3/COSMIC constellation. Geophys. Res. Lett. 36, L03808 (2009). doi:10.1029/2008GL036802

J. Wickert et al., Atmospheric sounding by GPS radio occultation: First results from CHAMP. Geophys. Res. Lett. 28(17), 3263-3266 (2001)

C.S. Zerefos et al., Evidence of gravity waves into the atmosphere during the March 2006 total solar eclipse. Atmos. Chem. Phys. 7, 4943-4951 (2007)

J.B. Zirker, Total eclipse of the sun. Science 210, 1313-1319 (1980) 